\title{
Evaluation of Eucalyptus tereticornis, Tagetes minuta and Carica papaya as stored maize grain protectants against Sitophilus zeamais (Motsch.) (Coleoptera: Curculionidae)
}

\author{
Simbarashe Muzemu ${ }^{1, *}$, James Chitamba ${ }^{2, *}$, Benny Mutetwa ${ }^{1}$ \\ ${ }^{1}$ Department of Horticulture, Midlands State University, P. Bag 9055, Gweru, Zimbabwe \\ ${ }^{2}$ Department of Agronomy, Midlands State University, P. Bag 9055, Gweru, Zimbabwe
}

\section{Email address:}

smuzemu@gmail.com (S. Muzemu),chitambajc@gmail.com (J. Chitamba)

\section{To cite this article:}

Simbarashe Muzemu, James Chitamba, Benny Mutetwa. Evaluation of Eucalyptus tereticornis, Tagetes minuta and Carica papaya as Stored Maize Grain Protectants against Sitophilus zeamais (Motsch.) (Coleoptera: Curculionidae). Agriculture, Forestry and Fisheries. Vol. 2, No. 5, 2013, pp. 196-201. doi: 10.11648/j.aff.20130205.13

\begin{abstract}
Sitophilus zeamais (Motsch.) is an important storage pest of maize grain in several parts of Africa including Zimbabwe. Although synthetic pesticides are effective at controlling the pest, environmental and health hazards of these chemicals are of increasing concern. The study assessed efficacy of botanical leaf powders of Eucalyptus tereticornis, Tagetes minuta and Carica papaya in controlling S. zeamais using rates of $5 \mathrm{~g}, 10 \mathrm{~g}$ and $20 \mathrm{~g}$ per $200 \mathrm{~g}$ of open pollinated maize grain (variety ZM421). The trial was laid in a completely randomised design (CRD), with 12 treatments replicated three times. The grain was put in a freezer at $-4^{\circ} \mathrm{C}$ for a fortnight, before the botanicals were added, to kill any prior sources of weevil inoculum and eggs which might be already pre-existing in the grain. $200 \mathrm{~g}$ maize grain was infested with 200 three week old unsexed pure culture weevils in $750 \mathrm{ml}$ jars. After 14, 28, 42, 56 and 70 days, weevils were sieved and their mortality determined. Percentage grain weight loss was assessed after 35 days post pests introduction. There were significant differences $(p<0.05)$ in number of weevil mortality and grain weight loss among treatments and their application rates. The findings showed that conventional chemical control was most effective than all botanicals used. E. tereticornis was the most effective of all the botanical pesticides at an application rate of $20 \mathrm{~g}$ as evidenced by high weevil mortality and less grain weight loss. It was concluded that botanicals have storage pesticidal properties to suppress $S$. zeamais in maize grain and could be used as an alternative control option to synthetic pesticides.
\end{abstract}

Keywords: Eucalyptus tereticornis, Tagetes minuta, Carica papaya, Stored Maize Grain Protectants, Sitophilus zeamais

\section{Introduction}

Maize (Zea mays L.) is a major food security crop in Africa and it is usually stored to provide food reserves and also seed materials for planting [1]. Maize is a staple food of Zimbabwe and is widely grown by smallholder farmers who contribute $50 \%$ to national production. In Sub Saharan Africa, maize is a staple food for an estimated $50 \%$ of the population [2]. Despite high maize yields, losses in storage are high due to maize weevil, Sitophilus zeamais (Motsch.), especially among smallholder farmers. In Zimbabwe, the pest causes huge losses in storage if grain is not protected and it adversely affects food security at smallholder farmer level. Under serious infestations, maize weevil can cause grain losses of up to $90 \%$ on smallholder farms [3]. Boxall et al. [4] reported that grain weight loss of $12-20 \%$ caused by the maize weevil is common and up to $80 \%$ loss may occur for untreated maize grain stored in traditional structures in tropical countries.

In the world, maize is ranked third after wheat and rice in terms of leading crop production [5]. It is a high yielding crop attaining an average yield of $8 \mathrm{t} / \mathrm{ha}$, easy to process, readily digested and cheaper to produce than any other cereals. However, smallholder farmers live in remote communities and cannot readily sell their produce. Most of them store maize grain for periods of 6-8 months as strategic grain reserves in times of need and the grain during this period is susceptible to maize weevil attack. In Zimbabwe, maize is used for other non-food purposes such as beer brewing and in exchange for goods and services. It is critical in raising rural incomes and stimulating broad-based economic growth [5].

S. zeamais is an important field and storage pest of maize 
grain in several parts of Africa [6]. Maize weevil damage results directly in loss of both maize grain quantity and quality and may also reduce future maize production for farmers who use retained grain as seed. S. zeamais is also responsible for the reduction in aesthetic and market value, germinability and nutritive value of maize [7]. The use of synthetic pesticide in the control of weevils is broadly recommended, but resource poor farmers in developing countries like Zimbabwe often cannot afford them due to inauspicious macro-economic environment in the country [5]. Moreover, the increasing occurrence of pesticide resistance [8] and environmental concerns about the use of synthetic pesticides means that alternative control methods are required. This is exacerbated by the fact that the pesticides toxicity also has adverse effects on non-target organisms [9] as well as the environment that leads to acute or chronic poisoning. These pesticides and containers cause land pollution ending up in river systems affecting aquatic life. Therefore, control programs should rely on safe, low cost and locally available alternative tactics that prevent maize grain losses by controlling storage grain losses due to pests [1]. Moreover, Muzemu et al. [10] reported that pesticides are expensive, not readily available and pose health problems to consumers due to their toxicity since many have some residual effect.

The bulky of African grain comes from small scale farm holdings and these traditional farmers use different kinds of plant products to control pests. The precise strategy used by different communities varies from place to place and appears to depend partly on the type and efficacy of suitable materials available in different locations [11]. There are a variety of botanicals which are being used by resource poor farmers in different parts of Zimbabwe such as Eucalyptus tereticornis and Tagetes minuta [12] but there is need for their evaluation so as to find out the most effective and locally available. Many African plants are potential sources of pesticide and have been shown to contain either anti-feedant, repellent or insecticidal compounds that enable the crude plant material or an extracted active compound to protect stored product [13]. Research on plants with repelling effect on pests is being done in some parts of Africa, but has not yet gained much publicity [14].

Most botanicals are locally available to the farmers and they are environmentally friendly. Botanicals are quick to stop feeding of insect pests and often cause immediate paralysis or cessation of feeding, but they may not cause the insect's death for hours or days. Botanicals degrade rapidly and are considered safer to the environment than synthetic chemicals [1]. The use of botanicals will thus help reduce post harvesting losses and costs. In the past, the efficacy of a particular control measure was the most important consideration but nowadays the safety of the workers, effects on the environment and product quality are issues that represent high priority. If sufficiently exploited, botanical pesticides can play a big role in reducing pollution, health risks and crop losses to pests [15].

Considering the economic significance of maize crop, the devastating nature of $S$. zeamais to the crop, as well as the availability of botanical materials in the country; it is imperative that the present study was undertaken with the overall objective of assessing the efficacy of Carica papaya, E. tereticornis and T. minuta leaf powders as alternatives to synthetic pesticides for the control of maize weevil, $S$. zeamais.

\section{Materials and Methods}

\subsection{Study Site}

The trial was carried out at University of Zimbabwe in the Biological Science's Entomology Laboratory, located on longitude $17^{\circ} 47^{\prime} 02^{\prime \prime} \mathrm{S}$ and latitude $31^{\circ} 03^{\prime} 11^{\prime \prime} \mathrm{E}$, at an altitude of $1207 \mathrm{~m}$ above sea level. The area falls under Natural Region II of Zimbabwe's agro-ecological zones, with an average annual rainfall and temperature of $800-1000 \mathrm{~mm}$ and $25-30^{\circ} \mathrm{C}$ respectively.

\subsection{Experimental Design and Procedures}

Fresh leaves of E. tereticornis, C. papaya and T. minuta were collected and shed-dried naturally at temperatures between $25 \pm 2^{\circ} \mathrm{C}$ until they became crisp dry. The dried leaves were crushed into powder using pestle and mortar. One pure maize open-pollinated variety, ZM421 obtained from ARDA Seeds, was used in the experiment. Weevils used in the experiment were obtained from Crop Protection Research Institute in Harare.

A completely randomised design (CRD) was used to arrange the $750 \mathrm{ml}$ jars in the laboratory to minimise door effects and each treatment was replicated three times. The maize grain was thoroughly cleaned using a $1 \mathrm{~mm}$ sieve-mesh screen so as to remain with intact testae, which were disinfested by keeping the grain in a freezer at $-4^{\circ} \mathrm{C}$ for two weeks. The grain moisture was in the range of $12-13 \%$. Approximately $200 \mathrm{~g}$ of maize grain was placed into each of the $750 \mathrm{ml}$ jars with perforated lids. The botanical treatments were applied at rates of $5 \mathrm{~g}, 10 \mathrm{~g}$ and 20 g. Deltamethrin was used as the control at the rate of $0.175 \mathrm{~g} \mathrm{jar}^{-1}$. The grain was thoroughly mixed with the botanical leaf powders before introducing the pests. Two hundred three-week old unsexed weevils were introduced into each jar. Camel hair brush was used for collecting and the tweezers for holding the pests. The jars were placed in the shelves at a temperature of $28 \pm 2^{\circ} \mathrm{C}$ and relative humidity of $70 \pm 5 \% .1$ and $4.7 \mathrm{~mm}$ screen meshes were used for separating grain, dust and pests.

Weevil mortality was assessed 14, 28, 42, 56 and 70 days after the introduction of the pests. The grain was sieved and the numbers of live and dead pests were counted from each jar to obtain weevil mortality. The following formula was used to calculate the percentage weevil mortality: 
Percentage weevil mortality

$$
=\frac{\text { number of dead pests }}{\text { total number of all the pests }} \times 100
$$

After 70 days of incubation the grain was sieved, dust removed and the clean grain weighed and expressed as a percentage weight loss of the original weight, using the following formula:

$$
=\frac{\begin{array}{l}
\text { Percentage grain weight loss } \\
\text { (original weight }- \text { weight after } 70 \text { days })
\end{array}}{\text { original weight }} \times 100
$$

The weevil mortality counts were transformed using Duncan multiple range test to normalise the data. A general analysis of variance (ANOVA) for weevil mortality and percentage grain weight loss was conducted using GenStat $14^{\text {th }}$ Edition of 2011. Mean separation was done by using least significant difference (LSD) to compare the significant differences between treatments at 5\% level of significance.

\section{Results}

\subsection{Effect of Different Botanical Concentrations on Weevil Mortality}

There was a significant difference $(\mathrm{p}<0.001)$ in mortality rate of weevils due to botanical pesticides, with $E$. tereticornis at $20 \mathrm{~g}$ being most effective compared to other botanicals at day 14. C. papaya and T. minuta had the least

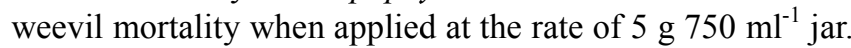

\begin{tabular}{|c|c|c|c|c|c|c|}
\hline \multirow{2}{*}{ Treatments } & \multirow{2}{*}{ Dosage (g/200g grain) } & \multicolumn{5}{|c|}{ S. zeamais mortality (\%) } \\
\hline & & Day 14 & Day 28 & Day 42 & Day 56 & Day 70 \\
\hline \multirow{4}{*}{ C.papaya } & 5 & $15.44^{\mathrm{a}}$ & $45.64^{\mathrm{a}}$ & $59.58^{\mathrm{bc}}$ & $49.82^{\mathrm{a}}$ & $82.91^{\mathrm{c}}$ \\
\hline & 10 & $32.40^{\mathrm{b}}$ & $56.68^{\mathrm{b}}$ & $68.92^{\mathrm{d}}$ & $72.44^{\text {bcd }}$ & $47.38^{b}$ \\
\hline & 20 & $47.02^{d}$ & $63.64^{c}$ & $56.27^{\mathrm{b}}$ & $75.81^{\text {cde }}$ & $47.74^{\mathrm{b}}$ \\
\hline & 5 & $18.71^{\mathrm{a}}$ & $47.38^{\mathrm{a}}$ & $56.99^{\mathrm{bc}}$ & $69.35^{\mathrm{bc}}$ & $47.89^{b}$ \\
\hline \multirow[t]{2}{*}{ T. minuta } & 10 & $39.37^{\mathrm{c}}$ & $64.11^{\mathrm{c}}$ & $86.50^{\mathrm{e}}$ & $77.78^{\text {cde }}$ & $46.71^{\mathrm{b}}$ \\
\hline & 20 & $48.08^{d}$ & $63.64^{\mathrm{c}}$ & $55.45^{\mathrm{b}}$ & $79.44^{\mathrm{de}}$ & $47.34^{\mathrm{b}}$ \\
\hline \multirow{3}{*}{ E. tereticornis } & 5 & $50.05^{d}$ & $65.90^{\mathrm{cd}}$ & $68.69^{d}$ & $65.11^{\mathrm{b}}$ & $38.03^{\mathrm{ab}}$ \\
\hline & 10 & $60.19^{e}$ & $68.43^{\mathrm{e}}$ & $48.73^{a}$ & $91.13^{\mathrm{f}}$ & $42.41^{\mathrm{b}}$ \\
\hline & 20 & $65.32^{f}$ & $67.94^{\mathrm{de}}$ & $62.82^{\text {cd }}$ & $82.09^{e}$ & $43.67^{b}$ \\
\hline Deltamethrin & 0.175 & $89.53^{\mathrm{g}}$ & $75.98^{f}$ & $59.74^{\mathrm{bc}}$ & $46.12^{\mathrm{a}}$ & $28.94^{\mathrm{a}}$ \\
\hline
\end{tabular}
The highest mortality was recorded at $0.175 \mathrm{~g}$ of delthamethrin (Table 1).

Means followed by different superscript letters within a column are significantly different at $5 \%$ level of probability

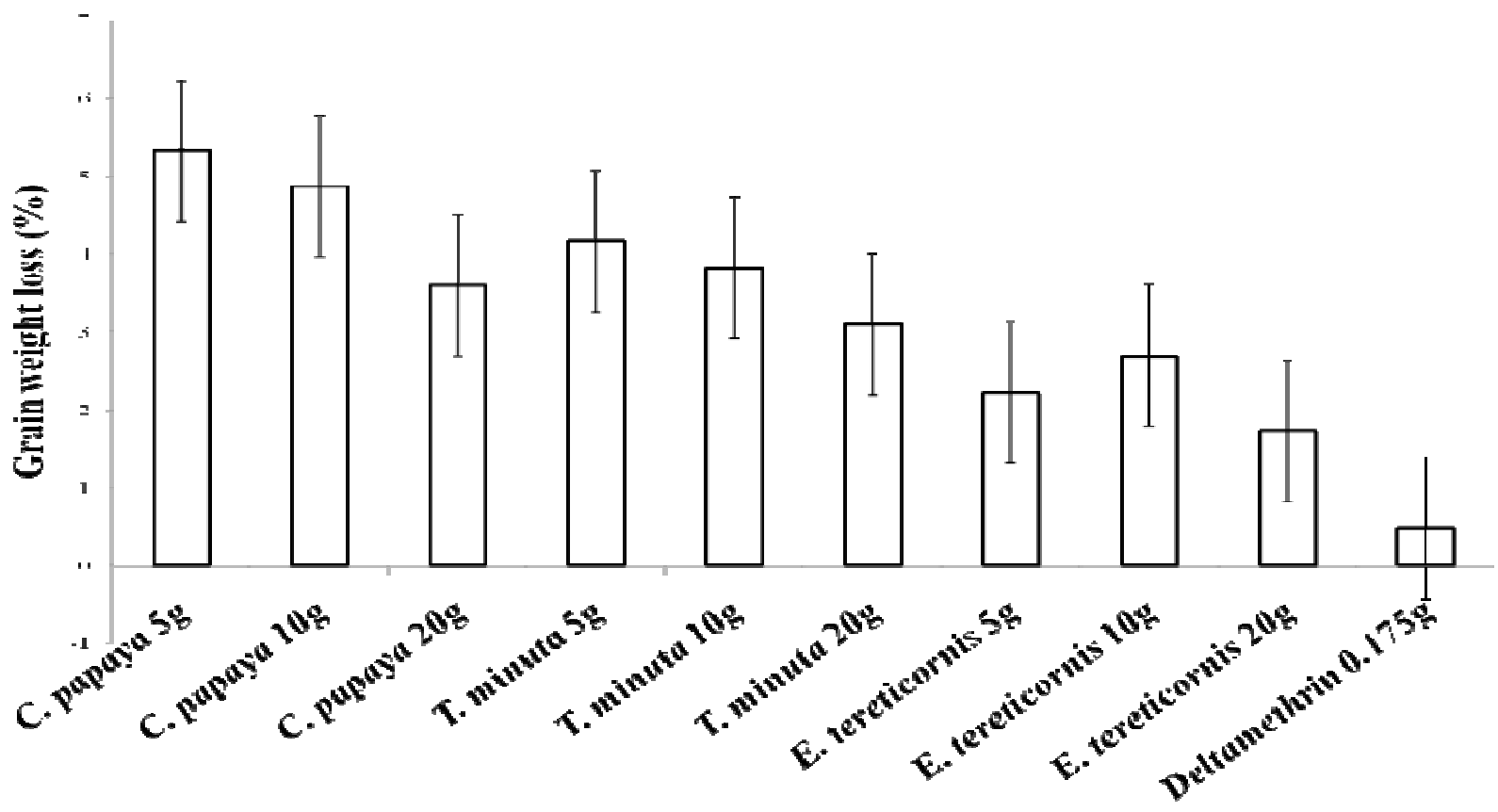

Figure 1. Effect of botanical powders on maize grain weight loss 
At day 28 , there was a significant difference $(\mathrm{p}<0.001)$ in mortality rate of weevils due to botanical pesticides with $E$. tereticornis at $20 \mathrm{~g}$ being the most effective compared to other botanicals. Generally, C. papaya and T. minuta at the rate of $5 \mathrm{~g}$ had higher mortalities at 28 days compared to at 14 days. The mortality rate of these botanicals was quite high at $20 \mathrm{~g}$ rate though still lower compared to those attained at the same rate by using E. tereticornis, with deltamethrin at $0.175 \mathrm{~g}$ still having the highest mortality rate (Table 1).

At day 42 , significant difference $(p<0.001)$ in weevil mortality rate was observed among the botanical pesticides, with E. tereticornis at $5 \mathrm{~g}$ and $20 \mathrm{~g}$ being more effective compared to other botanicals. However, C. papaya was also effective at $10 \mathrm{~g}$ at day 42 (Table 1).

At day 56, significant difference $(\mathrm{p}<0.001)$ in weevil mortality was observed among the different botanical pesticides. E. tereticornis was the most effective at $10 \mathrm{~g}$ compared to other botanicals though E. tereticornis at rate of $20 \mathrm{~g}$ was still very effective in controlling maize weevils. C. papaya was the least effective in controlling the maize weevils (Table 1).

At day 70 , there was a significant difference $(p<0.05)$ in weevil mortality among the botanical pesticides, with $C$. papaya being most effective at $5 \mathrm{~g}$ followed by $T$. minuta at the same rate of $5 \mathrm{~g}$. There were now few maize weevils left in the deltamethrin treated maize, hence the lower mortality rate (Table 1 ).

\subsection{Effect of Different Botanical Concentrations on Grain Weight Loss}

There was a significant difference $(\mathrm{p}<0.001)$ in grain weight loss among the different treatments. E. tereticornis resulted in the least grain weight loss due to weevil damage at all the 3 application rates of $5 \mathrm{~g}, 10 \mathrm{~g}$ and $20 \mathrm{~g}$ followed by $T$. minuta. $C$. papaya resulted in the greatest maize grain weight loss at application rates of $5 \mathrm{~g}$ and $10 \mathrm{~g}$ (Figure 1).

\section{Discussion}

Results from the present study indicate that botanical leaf powders can be used to control S. zeamais in stored maize grain. The utilisation of different plant products as stored crop grain protectants has been reported by Araya and Emana [16] as well as Mulungu et al. [1]. Maize grain treated with the synthetic pesticide deltamethrin had the highest percent weevil mortality compared to the botanicals. This indicates that deltamethrin is effective against $S$. zeamais in stored maize grain.

Among the botanicals used in the study, E. tereticornis leaf powder significantly reduced the number of maize weevils by at least $65 \%$. This then shows that the resource poor farmers can use botanicals in the control of maize weevils. The effects of different plant materials on maize weevils may depend on several factors such as chemical composition and maize weevil species susceptibility [17]. In the current study, mortality of $S$. zeamais varied with the rates used, with the highest on E. tereticornis at application rate of $20 \mathrm{~g}$ over the 70 day period. This is consistent with findings by Mbaiguinam et al. [18] where ground Eucalyptus saligna leaves showed that grinding the leaves allows them to release their insecticidal effect on weevils more effectively. Wheeler et al. [19] also reported that dried ground leaves provided greatest protection of maize and sorghum grains against attack by $S$. zeamais, Rhyzopertha dominica and Sitotroga cerealella. The results showed that the efficacy of botanical pesticides decreases with time as shown by the reduced mortality percentages from day 70 . This may suggest that botanicals need constant reapplications for them to offer continual protection of the grain against maize weevils [20].

The use of the three botanical powders promoted higher insect mortality in the study as a result of physical barriers effect of the leaf powders. This can be attributed to the fact that the leaf powder has the tendency of blocking the spiracles of the insects thereby impairing respiration leading to the death of the parent and F1 progeny weevils [1]. This is consistent with Araya and Emana [16] who reported that the insecticidal activities of the plant powders are variable and broad and dependent on different factors like the presence of bioactive chemicals which need to be identified, isolated and manufactured in the factory for pest management.

Hall [21] observed that leaf powder of Eucalyptus have a repellent effect on olfactory and gustatory system of $S$. zeamais. Moreover, Mulungu et al. [1] reported that the crushed dry Eucalyptus leaves have been observed to having their repellent smell which can be utilised for effective control of stored maize grain pests like S. zeamais. However, the present study showed that plant species, dosage of powder applied and the exposure time greatly influenced the degree of repellence by the botanical powders.

The effectiveness of the botanical powders used can be due to the fact that they acted as fumigants or repellents; while feeding on whole grains, $S$. zeamais picks up lethal doses of the plant leaf powders treatments thereby leading to stomach poisoning. On the other hand, ground leaf powders of C. papaya, Eucalyptus and T. minuta used in the experiment have insecticidal effect work by inhibiting weevil movement or inducing desiccation. These results agree with Mulungu et al. [1] and Hall [21]. Moreover, Parwada et al. [22] reported that T. minuta leaf powder may have antifeedant activity on the weevils. In addition to causing adult mortality, the botanical leaf powders either completely hindered or significantly reduced progeny emergence indicating their potential for use in the management of the maize weevil. Similar work by Owusu [23] indicates that some local plant materials have insecticidal and antifeedant properties which could inhibit the pest activities of $S$. zeamais. Other earlier reports with similar trends to this study have shown that the insecticidal, repellent or antifeedant and the development of inhibiting effects of various plants parts and plant products on $S$. 
zeamais showed varying degrees of success [24].

Among the botanical leaf powders treatments, highest grain weight loss was experienced in the maize grain treated with C. papaya over the 70 day exposure to $S$. zeamais weevils whilst the grain treated with E. tereticornis leaf powder and the synthetic deltamethrin had least grain weight loss. High grain weight loss in the Eucalyptus leaf powder treated maize grain can be attributed to the low weevil mortality and high weevil survival which resulted in the unchecked reproduction of the weevils thereby resulting in high weevil population which resulted in higher grain damage hence high grain weight loss. The findings are in agreement with Chiu [25] who observed that synthetic dusts like cypermethrin $1 \%$ dust is effective in protecting stored grain thereby reducing loss of grain weight.

Hall [21] and Parwada et al. [22] reported that ground plant extracts act by dehydrating and suffocating the weevil and also by reducing weevil movements thereby resulting in reduced grain damage and weight loss. The leaf powders of E. Tereticornis T. minuta and C. papaya could also have reduced grain weight loss due to the fact that they reduce the relative humidity on the surface of the grain thereby inhibiting egg laying and larval development of the weevils. This concurs with the findings by Aslam and Suleman [26]. However, the results from the present study are inconsistent with Mulungu et al. [1] who reported that $C$. Papaya leaf powder was more effective in controlling $S$. zeamais than Eucalyptus leaf powder.

Generally, the results indicate that the higher the parent weevil mortality, the lower the live numbers of F1 progeny and the lower the stored grain damage and weight loss.

\section{Conclusion}

The present study showed that the effectiveness of botanical pesticides decreases with time and they therefore need constant reapplications. The effectiveness of botanical pesticides was most observed when E. tereticornis leaf powder was used to treat maize grain at $20 \mathrm{~g}$. There was little mortality rates of maize weevils at application rates of $5 \mathrm{~g}$ and $10 \mathrm{~g}$ for all the botanicals though it seemed there was a significant mortality rate for C. papaya at $5 \mathrm{~g}$ after 70 days. The toxic and repellent action of the leaf powders of $E$. tereticornis, T. minuta and C. papaya on S. zeamais indicates that these botanical products can be utilised as good alternatives to synthetic pesticides in the control of the pest in stored maize grain. Where synthetic grain protectants like deltamethrin and pirimiphos-methyl are unavailable or unaffordable, small holder farmers can use traditional techniques to confer some measure of protection of their maize grain again weevils, but this may only be guaranteed at high levels of botanical concentration.

\section{Acknowledgements}

The authors would like to acknowledge the University of Zimbabwe's Biological Science Department for their unwavering support and allowing the experiment to be done in their laboratory. Special gratitude goes to ARDA Seeds and Crop Protection Research Institute for providing the maize grain and pure culture weevils used in the work respectively.

\section{References}

[1] Mulungu L.S., Lupenza G., Reuben S.O.W.M. and Misangu R.N. 2007. Evaluation of botanical products as stored grain protectant against maize weevil, Sitophilus zeamays (L.) on maize. Journal of Entomology, 4: 258-262.

[2] International Institute of Tropical Agriculture (IITA). 2009. Maize. IITA Publications, Ibadan. (http://old.iita.org/cms/details/maize_project_details.aspx). Accessed on 22/08/2013.

[3] Coyne D., Hoeschle-Zeledon I. 2001. Handbook major pests and diseases of important crops in Malawi. Typo-Druck-ROBdorf GbH, RoBdorf, Germany.

[4] Boxall R.A., Brice J.R., Taylor S.J. and Bancroft R.D. 2002. Technology and management of storage, pp. 141-232. In Golob P., Farrell G. and Orchard J.E. (eds). Crop Post-harvest: Science and Technology. Volume 1 Principles and Practice. Blackwell Science.

[5] Rukuni N., Towonezvi P. and Eicher C. 2006. Zimbabwe revolution, maize research and Development. University of Zimbabwe Publication, Harare, Zimbabwe. pp. 208-212.

[6] Iloba B.N. and Ekrakene T. 2006 Comparative assessment of insecticidal effects of Azadirachta indica, Hyptis suaveolens and Ocimum gratissimum on Sitophilus zeamais and Callosobruchus maculantus. Journal of Biological. Sciences, 6: 626-630.

[7] Pingali P.L. and Pandey S. 2001. Meeting world maize needs Technology opportunities and priorities for the public sector. In: Pingali P.L. (ed). CIMMYT 1999-2000, World maize facts trends. CIMMYT, Mexico City.

[8] Golob P. 2002. Protection of farm stored grains against infestation by horn species in Tanzania. Journal of Stored Products Research, 29: 210-299.

[9] Chitamba J., Manjeru P., Chinheya C.C. and Handiseni M. 2013. Evaluation of legume intercrops on population dynamics and damage level of $R$. similis in banana (Musa spp.). Archives of Phytopathology and Plant Protection. (DOI: 10.1080/03235408.2013.821759).

[10] Muzemu S., Chitamba J. and Goto S. 2013. Screening of stored maize (Zea mays L.) varieties grain for tolerance against maize weevil, Sitophilus zeamais (Motsch.). International Journal of Plant Research, 3(3):17-22.

[11] Greenberg S.M., Showler A.T. and Liu T-X. 2005. Effects of neem-based insecticides on beet armyworm (Lepdoptera: Noctuidae). Insect Science, 12: 17-23.

[12] Gadzirayi C.T., Mutandwa E. and Chikuvire T.J. 2006. Effectiveness of maize cob powder in controlling weevils in 
stored maize grain. African Studies Quarterly, 8 No.4.

[13] Kubo I. and Nakanishi K. 1977. Insect repellants and antifeedants from African plants. In: Host plant resistance to pests. (Ed. Hedin P.A.) American Chemical Society, Washington, D.C. 157. pp. 165-178.

[14] Stoll G. 2000. Natural crop protection in the tropics, Verlog Joset Margrat, Science Book Germany.

[15] Kamatenesi-Mugisha M., Deng A.L., Ogendo J.O., Omolo E.O., Mihale M.J., Otim M., Buyungo J.P., Bett P.K. 2008. Indigenous knowledge of field insect pests and their management around Lake Victoria basin in Uganda. African Journal Environmental Science and Technology, 2(8): 342-348.

[16] Araya G. and Emana G. 2009. Evaluation of botanical plants powders against Zabrotes subfasciatus (Boheman) (Coleoptera: Bruchidae) in stored haricot beans under laboratory condition. African Journal of Agricultural Research, 4(10): 1073-1079.

[17] Akhtar Y., and Isman M.B. 2004. Comparative growth inhibitory and antifeedant effects of plant extracts and pure allelochemicals on four phytophagous insectspecies. Journal of Applied Entomology, 128: 32-38.

[18] Mbaiguinam M., Maoura N., Bianpambe A., Bono G. and Alladoumbaye E. 2006. Effects of six common plant seed oils on survival, eggs lying and development of the cowpea weevil, Callosobruchus maculatus (F.) (Coleoptera: Bruchidae). Journal of Biological Sciences, 6:420-425.

[19] Wheeler D.A., Isman M.B., Sanchez-Vindas P.E., Arnason
J.T. 2001 Screening of Costa Rican Trichilia species for biological activity against the larvae of Spodoptera litura (Lepidoptera: Noctuinidae). Biochemical Systematics and Ecology, 29: 347-358.

[20] Golob P. 2000. A practical assessment of food losses sustained during storage by small holder farmers in the Shire Valley Agricultural Development Area of Malawi. Department of the Tropical Products Institute. Slough G138. p. 32.

[21] Hall. D.W. 1990. Handling and storage of food grains in the tropical and subtropical areas. FAO, Rome, Italy.

[22] Parwada C., Gadzirayi C., Karavina C., Kubiku F., Mandumbu R. and Madumbu B.Z. 2012. Tagetes minuta formulation effect Sitophilus zeamais (weevils) control in stored maize grain. International Journal of Plant Research, 2(3): 65-68. DOI: 10.5923/j.plant.20120203.04.

[23] Owusu E.O. 2000. Effect of some Ghanaian plant components on control of two stored-product insect pests of cereals. Journal of Stored Products Research, 37(1): 85-91.

[24] Obeng-Ofori D. and Amiteye S. 2005. Efficacy of mixing vegetable oils with pirimiphos-methyl against the maize weevil, Sitophilus zeamais Motschulsky in stored maize. Journal of Stored Products Research, 41: 57-66.

[25] Chiu S.F. 1989. Recent findings on Meliaceae and other promising botanical insecticides in Chin. Journal of Plant Insects and Disease Protection, 36: 310-319.

[26] Aslam M. and Suleman M. 1999. Pest management of stored farm commodities. The Nation, 9: 5-5. 